\title{
Applying the lessons learnt in Asset Management around the world to the development of the AMPLE tool
}

\author{
A. J. Howard \\ Gutteridge Haskins \& Davey Ltd, UK
}

\begin{abstract}
This paper answers the two questions asked by rail asset managers, owners and stakeholders around the world:

- How can we drive logical, sustainable, cost effective asset management across the organisation to derive the benefits available through advanced asset management techniques? and;

- How do we achieve best value asset service delivery for the railway networks at the lowest sustainable triple bottom line cost for present and future generations of customers and stakeholders?

The lessons we have learnt in asset management from around the world over the last twenty years by accumulating knowledge from traditional learning systems have been applied to a web based program learning environment. By researching and understanding the key success factors for cost effective and sustainable asset management improvements across infrastructure rich businesses in both the private and public sectors, and web enabling this information, we now have a powerful on line encyclopaedia of asset management knowledge. By working with clients and users the ideas have formed into a product now known as AMPLE the Asset Management Program Learning Environment. This paper describes AMPLE and the way it assists clients to answer the above questions and importantly, incorporate the results in their work practices, attitudes and culture.
\end{abstract}

Keywords: infrastructure asset management, training, change management, best practice, benchmarking. 


\section{Background}

Analysis of client feedback concluded that the greatest benefits in strategic asset management could be derived if organisations were able to:

- Drive asset management improvements across their entire enterprise, including diverse business units such as are found in the large railway companies;

- Implement cost effective training of staff at various levels in all aspects of asset management; and

- Tailor the pace of asset management improvement to suit individual organisations and divisions.

AMPLE is the outcome of many years involvement in infrastructure service delivery. It is the latest in a range of web-based tools that have been developed to try and meet the needs of infrastructure owners, managers and other stakeholders.

Over the last nine years, AMPLE has developed from its first commission with one of the largest portfolio managers in the world; the Brisbane City Council, to whole-of-Government Asset Management Systems for the Australian State Governments of Queensland and the Northern Territory. More recently, AMPLE was released by the Water Environment Research Foundation (WERF) in the USA, as their asset management knowledge management tool known as Sustainable Infrastructure Management Program Learning Environment (SIMPLE), and further development is in progress for a rail-specific variant.

\section{What is AMPLE?}

AMPLE is a web-enabled knowledge management system whose purpose is to present a means by which organisations and their staff can gain an understanding of:

- The principles of life cycle asset management from basic to advanced infrastructure asset management in a step by step process; (three levels);

- The essential components of a state of the art asset management improvement program at sufficient detail to gain a sound understanding; and

- Enough "how to do it" information to enable users to drive their individual improvement programs.

The current AMPLE tool is three years into a four-year development program that will deliver a product that includes all aspects of best appropriate practice asset management for the full range of infrastructure industries from roads, to drains, to water, to rail.

The objective of this product is to provide a web based asset management learning environment that will assist infrastructure rich businesses to drive sustainable asset management improvements, cost effectively. It provides a webbased knowledge management system that can be implemented over several years from basic Level 1 up to advanced Level 3 Life Cycle Infrastructure Asset Management. To understand the modules that make up the total tool we draw 
your attention to the later sections, but first it is important to understand the philosophy that is driving the tool.

AMPLE has been developed to allow asset managers with varying degrees of experience to follow different tracks through this tool. It encourages the user to develop the required skills in a methodical process. By completing a simple questionnaire the user can easily identify the level at which they should enter the tool.

Figure 1 shows the home page for AMPLE, which directs users to the most appropriate path from the novice, to aware, and eventually through to the competent asset manager, via a series of asset management guidelines that provide a comprehensive picture of asset management. The whole program utilises a unique approach to driving sustainable asset management improvements including:

- $\quad$ The Step-By-Step approach (SBS);

- $\quad$ ISO 9000 based quality framework (TEAMQF);

- The Business Value Chain (BVC) proposition or approach;

- Confidence Level Rating (CLR) techniques for all investment decisions for capital, operations and maintenance; all linked to,

- The unique Business Risk Exposure (BRE) filtering methodology.

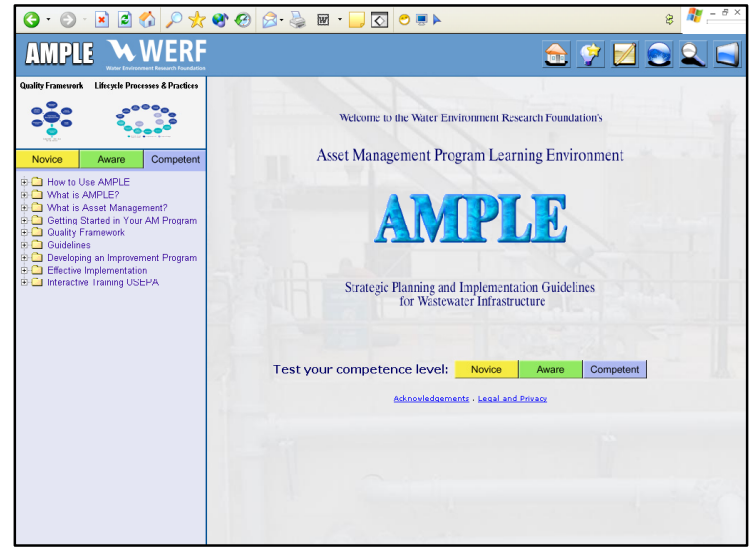

Figure 1: $\quad$ AMPLE home page.

\section{What does AMPLE achieve?}

These innovative approaches allow rail organisations to drive their Asset Management improvement programs by tailoring the approach to suit their individual organisation, rather than trying to make one model fit all organisations. Your businesses may be the same, or similar to others, (e.g. rail / utility) but your assets (the position in their life cycle and performance), your political environment, your regulatory framework, the consequences of failure and your financial viability and available resources / skills are all likely to be vastly different. 
AMPLE has been structured to allow the organisation to logically justify the level of sophistication that should be adopted for all activities and areas of investment, from capital to operations and maintenance to risk mitigation by incorporating unique approaches using CLR, BRE and BVC techniques at three different levels in a step by step process. The logic, philosophy and economic assessment processes built into this quality framework approach makes this a vital tool for all involved in the complex and costly world of sustainable infrastructure management.

\section{So what does AMPLE consist of?}

The tool consists of the following key modules.

\subsection{The quality framework (TEAMQF)}

The entire AMPLE tool is built around and underpinned by an ISO based quality framework, which we have called the Total Enterprise Asset Management Quality Framework, (TEAMQF), as shown in Figure 2.

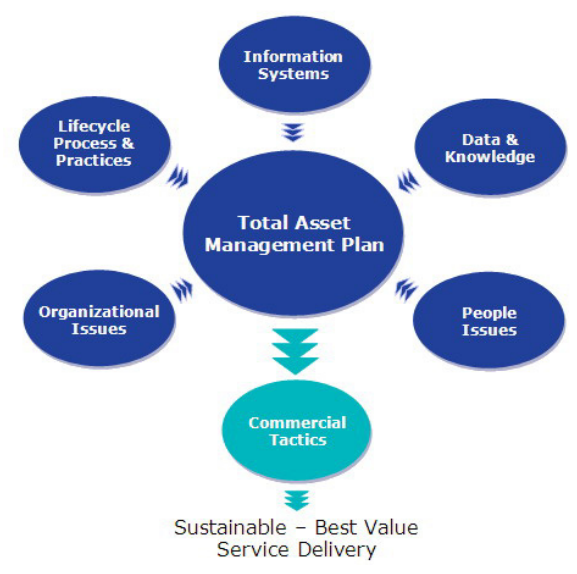

Figure 2: $\quad$ TEAMQF quality elements.

This framework allows staff to compare the organisation's performance in each aspect or function of the asset life cycle, which will:

- Assist organisations with the ability to acquire and maintain ISO accreditation;

- $\quad$ Provide the ability to monitor progress and improvements;

- Enable them to benchmark their input processes and compare themselves;

- Provide the logic to identify and develop the most cost effective improvement projects;

- Incorporate training modules that match to specific assets and levels of sophistication; and 
- $\quad$ Provide for the addition of case studies to demonstrate the benefits of making these changes / improvements.

The elements in this ISO based TQM /balanced scorecard approach cover what we believe are the primary quality elements including: Processes \& Practices, Data \& Knowledge, Information Systems, Total Asset Management Plans, People Issues, Organisational issues and Commercial Service Delivery Tactics.

\subsection{Best practice life cycle processes}

Underpinning this life cycle quality framework are a series of world's best practice guidelines, directing the user through a series of technical papers that are linked to the primary quality elements of TEAMQF. AMPLE is the catalyst for the research, collection, and web enabling of the world's best practice methodologies. As a program-learning tool, asset managers rely on a core set of guidelines so that when applied, they are confident that they will represent best practice to their organisation.

Figure 3 shows the life cycle processes or the journey of an asset throughout its lifecycle. These are the secondary quality elements of the primary quality framework element covering life cycle Processes. AMPLE enables the user / reader to link to a series of "best practice guidelines" that explain processes in a step by step manner up to world's best practice. Each individual organisation can use these and the resulting benefit / costs to drive asset management to a ' best appropriate practice ' (BAP) level to suit their organisation and asset portfolio.

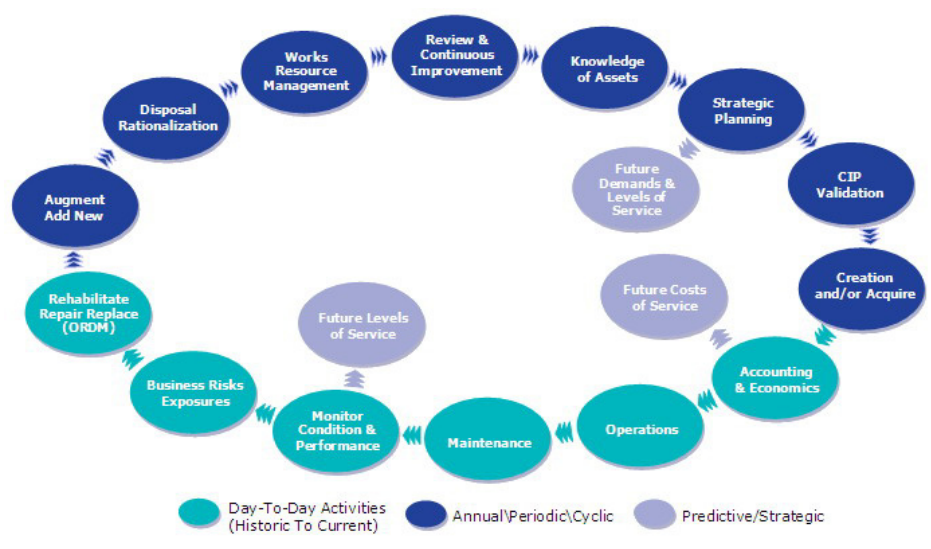

Figure 3: $\quad$ Asset life cycle.

\subsection{Gap analysis tools}

Central to the TEAMQF approach is the ability to determine the effectiveness of an organisation's management practices by identifying the distance between the current status (state of play) or the 'as is' one - and the desired state - the 'to be' for future sustainable business operations. Millions of pounds are at stake in the 
infrastructure management arena. Understanding the quality with which your assets are being managed is vital to staff, managers, directors and other stakeholders.

The gap analysis tools have been developed into three levels of sophistication: basic (Gap -Ex 1), intermediate (Gap -Ex 2) and advanced (GapEx 3), that enable users to understand their Current Quality Rating (CQR); compare and benchmark this with a vast database of similar organisations; and set their future improvement targets at a Best Appropriate Practice (BAP) level for both short-term and long-term objectives. This suite of gap analysis tools allows users to:

- Identify World's Best Practice (WBP) by links to the quality framework and the best practice guidelines;

- Identify and agree with the current level or status of practice, the Current Quality Rating (CQR);

- Observe how similar rail businesses perform and benchmark their organisation against them;

- Decide on a Best Appropriate Practice (BAP) level that suits the organisation and forms their future improvement target; and

- Identify all the improvement tasks / projects that will need to be completed to close the Gap.

\subsection{The benefits module}

The benefits module enables the user to determine the benefit that will be achieved in driving improvement by tying this back to the experience of other clients who have made these improvements.

Some of the benefits recognised include:

- Understanding the full economic cost of infrastructure service delivery;

- The real depreciation or consumption of assets based on the cost of their life extension or renewal;

- $\quad$ The whole of life cycle costs including allowances for environmental and social impacts; and

- The recognition of future renewal liabilities and operational issues.

We improve the effectiveness in the financial and technical management by improving our budget management, and improving our management of asset renewal and ageing in terms of cost and performance. We can then optimise our future life cycle costs by understanding and managing our business risk exposure. This is all processed in an intuitive online web tool, which allows the users and their business / enterprise to determine their overall benefits. These benefits are presented in terms of future life cycle cost, risk and performance benefits using both economic business case and ultimately in triple bottom line (TBL) terms.

\subsection{Asset management improvement plan module}

The Asset Management Improvement Planning module allows the determination of the most appropriate improvement program to deliver the 'best bang for your 
buck' while moving to a sustainable asset management organisation. This identifies the "quick wins" that can be achieved in the initial years using the unique Business Value Chain proposition (VC Management Technique) together with the gaps identified using the quality framework gap assessment. In simple terms it means that the enterprise will get the greatest benefit by doing those improvement projects, which have the biggest gap and the highest value to business proposition.

It also give users a full 'Roadmap' for the ultimate journey, with the users / enterprise controlling how far (to what level of BAP), how fast (over x years) and how much to spend on it (£xxxx Pounds per year). Of course the journey may not go down the main road and we have to remain flexible in our approach to ensure that we take the route that represents the 'best value' for each organisation. As we get further down the path, we learn more about our organisation and our assets (perpetual discovery) and we need to adapt and alter our approaches to get best result.

The key to the success of this module is its integration with the whole package, the alignments and linkages. The quality elements are rated against the best practice guidelines and their value is linked to the business value chain. The Gap Tool recognises this and identifies the actual improvements that need to be made to processes, practices, data, information systems, asset management plans, people and organisation issues, asset management plans and the commercial services delivery tactics to give our stakeholders the best value sustainable service delivery (most effective and efficient).

\subsection{Effective (sustainable) implementation module}

The effective implementation module covers all the issues that ensure successful implementations including planning, cultural change and people (staff) and organisational issues. The training or Learning Environment modules enable staff at all levels in the asset management program to learn using a web-based curriculum. These programs can be developed for industry and business covering all issues that need to be addressed. This covers all the people and organisational issues and the critical change management items that are essential to a fully successful asset management improvement program.

Because the transition to advanced asset management is really a change management process, AMPLE is designed to ensure that individual staff and organisational change issues are fully addressed and supported. Staff members are the most important assets in the TEAM process.

Successful implementation ensures that the full benefits of advanced asset management are achieved by the organisation. It is estimated that over $50 \%$ of the asset management benefits are derived in this area alone.

The AMPLE Tool has been structured to support Harvard University's eight steps to successful change in large organisations including:

- Create the need for change and quantify / document it;

- Create a group to guide the change across the enterprise;

- Develop a clear vision; strategy and action plan for what you want your asset management centric enterprise to look like; 
- Communicate this Vision to all stakeholders;

- $\quad$ Empower staff to undertake the actions required for change;

- Assist staff to make the change with tools, guidelines, strategies and training;

- Generate "quick wins" and show the benefits of this change; and

- Encourage the behaviour you want, and link this to your reward systems and enforce it with conviction where necessary.

\subsection{The learning environment - training modules}

There is little formal Advanced Infrastructure Asset Management training available around the world. There are great courses in many of the elements of an assets life cycle (e.g. maintenance and risk) and those directed specifically at the rail industry or asset type, however there is no program covering all aspects from an integrated quality framework perspective.

Rail organisations, utility and municipal businesses around the world have identified staff skills and training as a key risk due to:

- Their ageing workforces due to the "baby boom" effects;

- The greater staff mobility and reducing employment periods due to individual cultures and flexibility of travel etc. requiring more induction and specialist skills / asset related training;

- The impact of effectiveness and efficiency reviews has meant that there are less staff available to train and mentor staff in this specialist area; and,

- The rate of change in the world, in new techniques and new technology means that rail organisations will be in a continual state of change and this will make huge demands on our training and mentoring areas.

The training needs also need to be linked to our roles and responsibilities and cover from our junior staff or apprentices right up through our trades and supervisors to the professional engineers, accountants and other specialists through postgraduate degrees in this specialist area.

The training modules take staff through the critical aspects of asset management using the ten key building blocks of advanced asset management as shown in Figure 4.

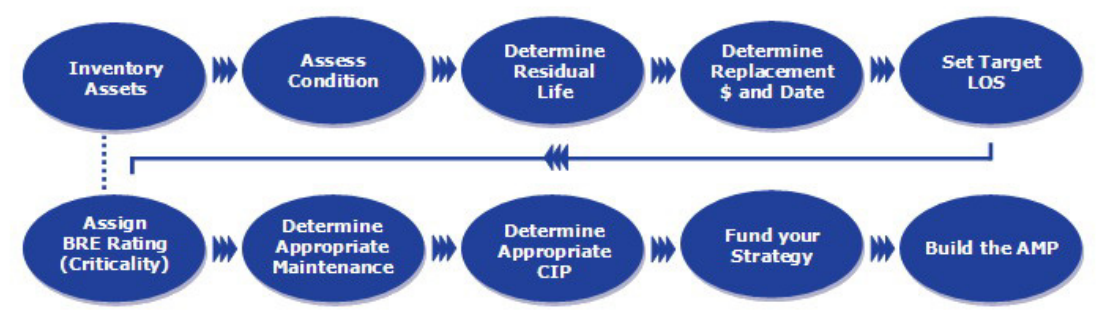

Figure 4: Ten key building blocks of AAM. 
Like all parts of the tool, even these training programs use the step by step techniques to ensure that trainees get to understand the best way to complete improved asset management practices using the scarce resources available to them.

The training modules teach users to develop an asset management plan (level 1) and users / trainees follow the fictional story of Tom, the General Manager and his staff as they learn how to deal with their asset / service delivery problems. The training modules under development include training programs for all parts of the rail system which then drive the asset management and analysis techniques further, to the 'best appropriate practice' in the most cost effective way for their organisations. It also shows Tom and his staff how they need to keep a balanced scorecard and care about the key success factors for sustainable change, and not just "how to do the immediate problems they face". These training programs are linked to the business processes, and the roles and responsibilities of the staff within them. In Australia we have a fully accredited Vocational Certificate course fully integrated with the AMPLE tool suite and we have started the development of a full Diploma and Post Degree qualifications forming elements of existing MBA courses.

\section{Conclusions}

The world of infrastructure asset management (IAM) has made incredible advancements over the last two decades. There have been many projects and activities that have driven the practices from an art towards a real science. However we have made many mistakes and have still not got the picture perfect.

Too many times we have seen great efforts and tremendous resources ultimately wasted due to just not getting all the pieces of the puzzle in place. IAM is not easy, it is not simple, but it is vital to the future of our railways.

We have watched a variety of approaches put forward and huge sums spent on research projects, which addressed only $0.025 \%$ of the issues critical to successful asset management and where these were often duplicated by bodies in over 6 different countries, creating a tremendous waste of limited resources and more importantly time.

It is time we stopped reinventing the wheel and concentrated on putting all our efforts into the continuous improvement of the best wheel available. The current model of AMPLE is by no means perfect, but it does address all the known risk factors, and it has been proven in actual organisations and is the result of the honest feedback from many throughout the industry. It presents a great vision for the future and its development offers incredible opportunities for infrastructure owners, managers, staff, regulators, users / ratepayers and politicians.

GHD believes that the development of AMPLE represents a giant leap forward in this area of railway infrastructure asset management. We believe that it offers a logical process by which organisations of any size and complexity will be able to better manage their valuable infrastructure and other similar associated assets. 
We challenge other interested parties to consider this approach and lets start the process of building even better rims, bearings, spokes and tires and stop reinventing the wheel itself.

This paper is number two in a trilogy of papers relating to improving infrastructure asset management around the world.

\section{References}

[1] World Wide. IPWEA Conference Adelaide - Lessons Learned in Infrastructure Asset Management - Paper 1, May 2005

[2] WAMI - Water Asset Management Magazine, Infrastructure Asset Management - A Global Approach and Model - Paper 3, January 2006

[3] AMQI Asset Management Quality International http://www.amqi.com/

[4] WERF - $\quad$ AMPLE project http://www.werf.org/AM/Template.cfm?Section=Home\&template=/CM/HT MLDisplay.cfm\&ContentID $=3003$

[5] NAMS Australia is an initiative of the IPWEA http://www.ipwea.org.au/nams

[6] NAMS New Zealand - the development of asset management best practice within New Zealand. http://www.ingenium.org.nz/nams

[7] WORLEY-GHD \& NAMS ALGENZ \& IPWEA Aust., International Infrastructure Management Manual, ALGENZ, First Edition, November 2000, ISBN 0-473-09137

[8] RBYRNE. - "The Evolution of Advanced Asset Management in Australia and New Zealand”. Paper to the USA General Accounting Office 2002 